\title{
Removal of Radioactive Cesium in Secondary Wastewater after Soil-washing Process
}

\author{
Juhyeok Lee ${ }^{\circledR} \cdot$ Jaeeun Kang ${ }^{\circledR} \cdot$ Won-Seok Kim $^{\dagger} \odot$ \\ Division of Advanced Nuclear Engineering, Pohang University of Science and Technology
}

(Received July 7, 2020; Revised August 13, 2020; Accepted August 19, 2020)

Objectives: Secondary wastewater is generated as the soil washing process proceeds to restore contaminated soil near the nuclear power plants (NPPs). In this study, we tried to evaluate the possibility of removing radioactive cesium from secondary wastewater through the adsorption process using illite.

Methods: To treat radioactive cesium present in wastewater, as an adsorbent, we used illite collected from Yeongdong, Chungbuk, and weathering illite artificially weathered by high temperature and acid treatment $\left(60^{\circ} \mathrm{C}\right.$, $0.01 \mathrm{M} \mathrm{HCl}$ ). Before and after weathering, the adsorption rate of illite at low concentrations of cesium and the desorption rate of adsorbents were compared and evaluated using a $1.5 \mathrm{ppm}$ of competitive potassium ion similar to that of groundwater.

Results and Discussion: When the illite was artificially weathered, the amount of frayed edge sites increased as the interlayer ions in the illite eluted. As a result of the adsorption and desorption experiments, it was confirmed that the adsorption rate of weathering illite increased by about $11 \%$ in acid condition $(\mathrm{pH} 3)$ and about $26 \%$ in neutral condition $(\mathrm{pH}$ 6.2), and the desorption rate of weathering illite decreased by about $6 \%$ in acid and neutral conditions, compared to Yeongdong illite. Yeongdong illite and weathering illite showed higher adsorption rate under neutral condition than acidic condition, because the surface of the illite became negatively charged at high $\mathrm{pH}$ so the reactivity with cesium present as a cation increased.

Conclusions: The artificial weathering process has improved the performance of illite as an adsorbent. We expect that weathering illite can be used as an effective adsorbent for the removal of radioactive cesium from NPP.

Keywords : Radioactive Cesium, Illite, Artificial Weathering, Adsorption, Desorption

The Korean text of this paper can be translated into multiple languages on the website of http://jksee.or.kr through Google Translator. 


\title{
연구논문
}

\section{토양 세척 후 발생하는 2차 폐수에서의 방사성세슘 제거 연구}

\author{
이주혁 ${ }^{\circledR} \cdot$ 강재은 $^{\circledR} \cdot$ 김원석 $^{\dagger}$
}

포항공과대학교 첨단원자력공학부

목적: 본 연구에서는 원자력발전소 인근 방사성 세슘으로 오염된 토양의 복원을 위한 토양 세척공정에서 발생되는 2차 폐수 중의 방사성세슘을 일라이트를 이용한 흡착공정을 통해 제거 가능성을 평가해 보고자 하였다.

방법: 본 연구에서는 폐수 중 존재하는 방사성세슘을 처리하기 위해 흡착제로 충북 영동에서 채취한 영동 일라이 트와 이를 고온산처리 $\left(60^{\circ} \mathrm{C}, 0.01 \mathrm{M} \mathrm{HCl}\right)$ 하여 인위적으로 풍화시킨 풍화일라이트를 이용하였다. 풍화 전후 저농도 세슘(1 ppm)에서의 일라이트의 흡착율을 비교하였으며, 경쟁 이온인 칼륨(1.5 ppm)을 이용하여 흡착제의 탈착율을 비교 및 평가하였다.

결과 및 토의: 일라이트를 인위적으로 풍화시키면, 일라이트 내 층간 이온이 용출되면서 풍화된 모서리면의 양이 증가하였다. 흡착 및 탈착 실험 결과, 풍화일라이트의 흡착율은 영동 일라이트보다 산성 조건(pH 3)에서는 약 $11 \%$, 중성 조건 $(\mathrm{pH}$ 6.2)에서는 약 $26 \%$ 증가하였으며, 탈착율은 산성 조건 $(\mathrm{pH} 3)$ 과 중성 조건 $(\mathrm{pH} 6.2)$ 에서 약 $6 \%$ 감소하는 것으로 나타났다. 영동 일라이트와 풍화일라이트는 산성 조건보다 중성 조건에서 흡착율이 높게 나타났 는데, 이는 높은 $\mathrm{pH}$ 에서 일라이트의 표면이 음전하를 띠게 되어 양이온으로 존재하는 세슘과의 반응성이 증가하 였기 때문이다.

결론 : 인위적인 풍화과정울 통하여 흡착제로써의 일라이트 성능을 개선시켰으며 이는 원자력발전소에서 발생하는 방사성세슘 제거를 위한 효과적인 흡착제로 활용될 수 있음을 시사한다.

주제어 : 방사성세슘, 일라이트, 풍화, 흡착, 탈착

\section{1. 서론}

원자력발전소 운영 및 해체 시 방사성핵종의 누출은 다양 한 방식으로 발생한다. 이 중 우라늄과 플루토늄의 핵분열 반응으로 발생하는 방사성세슘은 핵무기 폭발, 체르노빌과 후쿠시마 원자력발전소 사고, 그리고 원자력발전소 해체 시 와 같은 여러 원인을 통해 발생한다. ${ }^{1)}$ 실제로 후쿠시마 사 고 이후, 일본 최남단지역인 규슈지역을 제외하고 일본 전 역이 방사성세슘으로 오염되었다고 발표되었다. ${ }^{2)}$

국내외 원자력발전소 사고 및 해체 시 발생하는 방사성세 슘은 흡착성이 강하기 때문에 원전 주변 토양에 흡착되어 오염을 발생시킨다. ${ }^{3)}$ 이러한 오염된 토양에서의 방사성세슘 을 제거하는 방법으로는 토양 세척, 토양 세정 및 동전기 등 의 기술이 있다. ${ }^{4)}$ 이 중 토양 세척은 단시간 내에 광역의 토 양을 제염하고 용이성 및 경제적 효율성이 높아 광범위하게 사용되고 있다. ${ }^{5,6)}$ 특히, 방사성세슘은 매우 높은 용해도를 가지고 있기 때문에 토양 세척 시 발생하는 2 차 폐수에 가
장 많이 존재할 것으로 예상된다. ${ }^{7}$ 토양 세척은 세척수에 따라 결정되는데, 산 세척수를 이용한 제염 공정은 물을 이 용할 때보다 토양의 표면장력을 더욱 약화시켜 세슘과 토양 을 고효율로 분리시킬 수 있는 장점이 있으나, 다량의 산폐 액을 발생시킨다는 단점이 있다. ${ }^{4)}$ 이로 인하여, 세척수로 물을 이용하여 제염하는 공정 또한 개발되고 있다. ${ }^{4)}$ 따라서 토양 세척 후 발생하는 2 차 폐수는 산성 및 중성조건으로 존재할 수 있으며 2차 폐수에 존재하는 방사성세슘을 제거 하는 효율적인 방법이 필요하다.

최근 수중 환경으로부터 방사성세슘을 격리시키는 데 상당 한 연구가 진행되어오고 있으며, 방사성세슘 제염에 사용되는 기술로는 용매 추출, 침전, 이온교환, 그리고 흡착 등이 있다. ${ }^{8)}$ 이 중 흡착은 환경에서 방사성세슘을 제거하는 데 중요한 공 정이다. ${ }^{9)}$ 방사성세슘을 강하게 흡착하는 성질을 가진 점토 광물 중 하나인 일라이트 $\left(\left(\mathrm{K}, \mathrm{H}_{3} \mathrm{O}\right) \mathrm{Al}_{2}(\mathrm{Si}, \mathrm{Al})_{4} \mathrm{O}_{10}\left(\mathrm{H}_{2} \mathrm{O}, \mathrm{OH}\right)_{2}\right)$ 는 카올리나이트와 함께 우리나라 토양에 가장 많은 점토 광물이며, 가장자리에 풍화된 모서리면(frayed edge sites, 
$\mathrm{FES})$ 이라는 흡착 지점이 존재하기 때문에 흡착에 매우 효 율적인 광물로 알려져 있다. ${ }^{10,11)}$ 일라이트 구조는 2개의 $\mathrm{Si} / \mathrm{Al}$ 사면체판과 층간 양이온들에 의해 결합된 중심의 팔 면체판을 갖는 2:1층으로 구성된다. 일라이트는 일반적으로 층간 위치에 칼륨이 있으며 층간 간격은 약 $1.0 \mathrm{~nm}$ 이다. 하 지만 다른 1 가 및 2 가 양이온들이 층간에 존재하는 칼륨과 이온교환하여 층간 구조를 왜곡시킬 수 있다. ${ }^{12)}$ 수화된 칼 슘은 이 자리에 치환되어 일라이트의 층간 간격을 약 1.4 $\mathrm{nm}$ 로 팽창시킨다. ${ }^{13)}$ 이처럼 풍화는 수화 및 탈수 중간층 사 이에 부분적으로 확장된 영역을 생성하며, 이를 풍화된 모 서리면이라고 한다. ${ }^{14)}$ 이러한 풍화된 모서리면은 다른 1 가 및 2가 양이온보다 세슘을 선택적으로 흡착한다. 그리고 이 렇게 흡착된 세슘은 기존의 다른 흡착제보다 상대적으로 용 액으로 잘 탈착되지 않아 환경에서의 세슘의 이동성을 제어 하는 데 중요한 역할을 한다. ${ }^{15-17)}$ 이처럼 풍화된 모서리면의 존재여부는 세슘의 흡착율에 밀접한 연관이 있다. 일라이트 의 풍화 처리를 통한 풍화된 모서리면의 흡착 연구는 활발 히 연구되어오고 있으나, 대부분 중성 조건에서의 일라이트 의 흡착 연구로 집중되어져 왔다. 따라서, 2 차 폐수의 다양 한 $\mathrm{pH}$ 조건을 고려하여 산성 및 중성 조건에서의 일라이트 의 흡착 연구 및 흡착제로써의 안전성 평가를 위한 일라이 트의 탈착 연구가 필요하다.

따라서 본 연구에서는, 토양 세척 후 발생하는 2 차 폐수에 서의 세슘 제거를 위해 흡착제로 일라이트를 사용하였으며, 일라이트의 흡착 성능을 증가시키기 위하여 인위적인 풍화 를 진행하였다. 그리고 이를 확인하기 위해 SEM, BET, $\mathrm{XRD}$, 그리고 $\mathrm{TEM}$ 분석을 실시하였고 산성 및 중성조건에 서 흡착 실험을 진행하였다. 또한 흡착제의 안전성을 평가 하기 위해 풍화 전후 산성 및 중성조건에서의 물리적 및 화 학적 탈착 실험을 통해 일라이트의 세슘 탈착율 변화를 관 찰하였다.

\section{2. 실험방법}

\section{1. 재료 및 분석}

본 연구에서 흡착제로 사용한 일라이트는 영동 지방에서 채취한 영동 일라이트(Yeongdong illite, YD illite)로, 이를 체 거름으로 입자를 분류하여 75 150 $\mu \mathrm{m}$ 크기의 영동 일라이트 시료를 실험에 사용하였다. 산 세척수로는 옥살산, EDTA, 그 리고 인산 등이 사용되며 이 중 옥살산이 많이 사용되므로 $1 \mathrm{~L}$ 부피플라스크에 초순수 증류수 $1 \mathrm{~L}$ 를 넣고 Oxalic acid $0.090 \mathrm{~g}(1 \mathrm{mmol})$ 을 넣어 $\mathrm{pH} 3$ 인 $1 \mathrm{mM}$ 옥살산용액을 만들 어 사용하였다. ${ }^{6,18)}$ 중성 세척수로는 초순수 증류수 $(\mathrm{pH}$ 6.2)를 사용하였다. ${ }^{18)}$ 모의 폐수는 방사성 세슘(Cs-137 등)과 화학적 성질이 유사한 안정동위원소인 Cs-133을 사용하였다. 7.52 $\mu \mathrm{mol}(1.466 \mathrm{mg})$ 의 cesium nitrate $\left(\mathrm{CsNO}_{3}\right.$, Sigma-Aldrich,
Germany)를 옥살산 용액 및 증류수에 넣어 $1 \mathrm{ppm}$ 의 세슘을 포함한 모의 폐수를 제작하여 사용하였다.

탈착 실험 시, 토양 세척 후 발생하는 2차 폐수에 존재하 는 세슘을 흡착한 일라이트가 얼마나 탈착되는 지를 관찰 하기 위하여 세슘의 경쟁이온인 칼륨을 사용하였으며 농 도는 지하수와 유사한 환경을 기준으로 하였다. 따라서 칼 륨의 농도는 지하수 내 칼륨의 평균 농도인 약 $1.5 \mathrm{ppm}$ 으 로, $3.7 \times 10^{-2} \mathrm{mmol}(3.802 \mathrm{mg})$ 의 potassium nitrate $\left(\mathrm{KNO}_{3}\right.$, Sigma-Aldrich, Germany)를 산성 및 중성 용액에 넣어 탈착 용액으로 사용하였다. ${ }^{19)}$ 또한, 모든 실험에 대하여 삼중 (triplicate)으로 시료를 제작하였다.

풍화 전후 시료의 광물학적 형태 및 변화는 전계 방출형 주사 전자 현미경(SEM, JSM-7800F Prime, JEOL Ltd)을 사용하여 분석하였다. 시료는 백금 $(\mathrm{Pt})$ 코팅 $(20 \mathrm{~mA}, 15$ 초 $)$ 을 실시한 후 $500 \mathrm{~V}$ 조건에서 분석을 실시하였다. 시료의 비표면적은 BET 비표면적 분석기(BET, BELSORP-mini II, MicrotracBEL)를 사용하여 측정하였다. 시료 내 층간 간격의 변화는 구면수차보정 투과 전자 현미경(TEM, JEM-2200FS, $\mathrm{JEOL}$ )을 사용하여 측정하였으며, 전압 $200 \mathrm{keV}$ 에 상온에서 측정하였다. 또한 영동 일라이트와 풍화일라이트 시료의 결정학적 특성 및 변화 분석을 위해 XRD (X-ray diffraction) 분석을 실시하였다. XRD 분석은 $\mathrm{X}$-선 회절분석기(XRD, MiniFlex600, Rigaku, Japan)를 사용하여 측정하였으며, 회절 패턴은 $3 \sim 80^{\circ}, 2$ theta degree $(2 \theta)$ 구간에서 스텝크기 $0.01^{\circ}$ 로 측정하였다. X-선의 전류는 $15 \mathrm{~mA}$, 전압은 $40 \mathrm{kV}$ 를 사용 하였다. 흡착 및 탈착 전후 세슘의 농도는 유도결합플라즈마 질량분석기(ICP-MS, NexIon 300D, PerkinElmer)로 분석하 였다.

\section{2. 풍화}

풍화된 모서리면의 양을 증가시켜 영동 일라이트의 흡착 성능을 개선시키기 위하여 영동 일라이트를 고온산처리를 통해 인위적으로 풍화시켰다. 먼저, $100 \mathrm{~mL}$ 비커에 $0.01 \mathrm{M}$ 염산 $50 \mathrm{~mL}(\mathrm{pH} 1.0)$ 와 영동 일라이트 $1 \mathrm{~g}$ 를 넣어준 후 가 열 교반기(PC-620D, Corning)에서 $60^{\circ} \mathrm{C}, 300 \mathrm{rpm}$ 으로 1 일 동안 시료를 반응시켜주었다. ${ }^{20)}$ 이후, $50 \mathrm{~mL}$ 코니칼 튜브에 옮겨 담고, 원심분리기(Centrifuge, Eppendorf 5702)를 이용 하여 $3,000 \mathrm{rpm}$ 에서 20 분 동안 원심 분리시켰다. 시료에 의 한 $\mathrm{pH}$ 영향을 제거하기 위하여 원심 분리를 통해 침전된 풍화일라이트(Weathering illite)는 초순수 증류수를 이용하 여 상등액의 $\mathrm{pH}$ 가 6 이상의 값을 가질 때까지 반복적으로 세척하였다. 이를 $50^{\circ} \mathrm{C}$ 에서 24 시간 건조시킨 후 세슘에 대 한 흡착 및 탈착 실험에 사용하였다.

\section{3. 흡착}

고체 시료와 용액의 비율은 1:100으로, $50 \mathrm{~mL}$ 코니칼 튜 
브에 영동 일라이트 및 풍화일라이트 시료 $0.5 \mathrm{~g}$ 과 $1 \mathrm{ppm}$ 의 세슘 용액 $50 \mathrm{~mL}$ 를 넣어준 후, 충분한 흡착을 위하여 교반 기(Lab Companion, SK-300)를 이용하여 $250 \mathrm{rpm}$ 에서 3일 동안 교반시켜 주었다. ${ }^{21-23)}$ 흡착 반응 뒤 원심분리기를 이용 하여 $3,500 \mathrm{rpm}$ 에서 20 분간 원심 분리한 뒤 상등액을 채취 하였고, 상등액에 잔류한 세슘의 농도는 $2 \%$ 질산 용액으로 희석한 뒤 ICP-MS로 측정하였다. 시료의 세슘 흡착율은 초 기 세슘 농도 $\left(\mathrm{C}_{0}, \mathrm{mg} / \mathrm{L}\right)$ 와 흡착 뒤 상등액에 잔류한 세슘 농도 $\left(\mathrm{C}_{1}, \mathrm{mg} / \mathrm{L}\right)$ 의 차이를 이용하여 계산하였다(Eq. (1)). ${ }^{24)}$

$$
\operatorname{Efficiency}(\%)=\frac{\left(\mathrm{C}_{0}-\mathrm{C}_{1}\right)}{\mathrm{C}_{0}} \times 100
$$

\section{4. 탈착}

흡착된 시료는 탈착 실험을 위하여 오븐(Lab Companion, $\mathrm{OF}-21 \mathrm{E}$ )에서 $60^{\circ} \mathrm{C}$ 에서 24 시간 동안 건조시켰다. 탈착 실험 은 초순수 증류수 세척을 통한 물리적 탈착 실험과 경쟁 이 온과의 이온 교환을 통한 화학적 탈착 실험으로 나누어 진 행하였다. 화학적 탈착 실험에 앞서, 흡착 후 건조시킨 시료 에는 풍화된 모서리면에 흡착된 세슘 이외에 흡착제 표면에 묻어있는 세슘이 존재할 수 있기 때문에, 이를 제거하기 위 하여 초순수 증류수를 이용하여 세척하였다. 고체 시료와 용액의 비율은 $1: 100$ 으로, 흡착 실험과 동일한 코니칼 튜브 에 초순수 증류수 $50 \mathrm{~mL}$ 를 넣고 3 시간 동안 교반기를 이용 하여 $250 \mathrm{rpm}$ 에서 교반시켜 주었다. 이를 원심분리기로 $3,500 \mathrm{rpm}$ 에서 20 분간 원심 분리한 뒤 상등액을 채취하였 고, 상등액에 존재하는 세슘의 농도는 흡착 실험과 동일하 게 ICP-MS로 측정하였다. 초순수 증류수 세척은 상등액에 서 세슘이 측정되지 않을 때까지 세척하였고 본 실험에서는 4번 실시하였다.

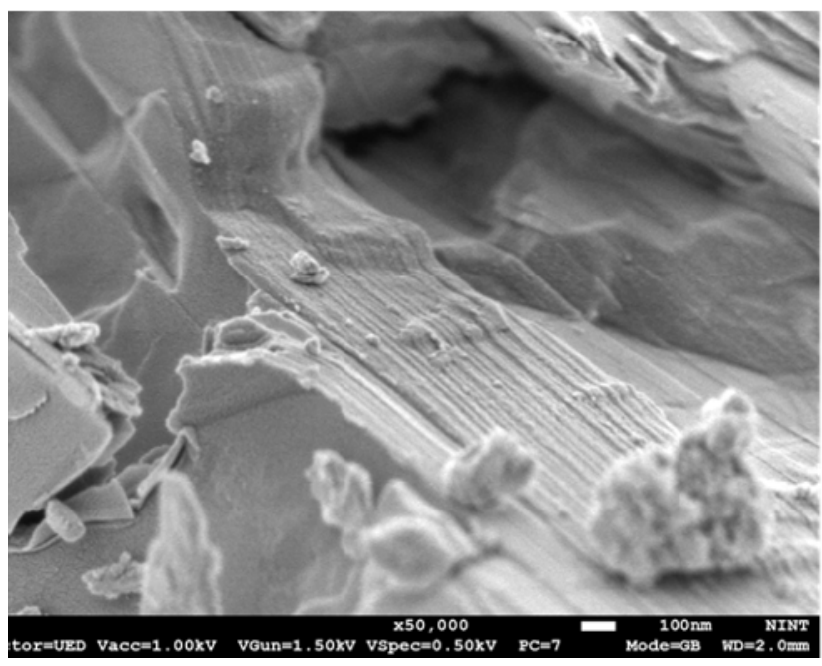

이후 시료를 오븐에서 $60^{\circ} \mathrm{C}$ 에서 24 시간 동안 건조시킨 후 화학적 탈착 실험을 진행하였다. 이온 교환을 위한 세슘의 경쟁 이온으로는 칼륨을 이용하였다. 건조시킨 시료에 1.5 $\mathrm{ppm}$ 의 $\mathrm{KNO}_{3}$ 용액 $50 \mathrm{~mL}$ 를 넣고 교반기를 이용하여 250 $\mathrm{rpm}$ 으로 교반시켰다. 반응 시간에 따른 탈착율을 관찰하기 위하여 탈착 용액 주입 후 $1 \mathrm{~h}, 6 \mathrm{~h}, 12 \mathrm{~h}, 24 \mathrm{~h}, 3 \mathrm{~d}, 7 \mathrm{~d}$, 그리고 $14 \mathrm{~d}$ 에 시료를 원심 분리 후 상등액에서 용액을 0.1 $\mathrm{mL}$ 채취하여 $2 \%$ 질산으로 100 배 희석 후 세슘의 농도를 $\mathrm{ICP}-\mathrm{MS}$ 를 이용하여 측정하였다. 측정된 세슘의 농도를 통 해 시간에 따른 영동 일라이트 및 풍화일라이트의 탈착율을 Eq. (1)을 이용하여 계산하였다.

\section{3. 결과 및 고찰}

\section{1. 영동 일라이트 및 풍화일라이트 시료의 특성}

영동 일라이트와 풍화일라이트의 광물학적 형태를 관찰 하기 위하여 SEM 분석을 수행하였다.

광물 시료들을 50,000 배 비율로 확대하여 보았을 때, Fig. 1 의 영동 일라이트 및 풍화일라이트 모두에서 판형 구조의 집합체가 관찰되었다. 하지만 SEM 이미지를 통해서는 수 $\mathrm{nm}$ 의 층간 간격 변화를 확인하기에는 한계가 있어, 풍화 정 도를 표면상으로는 확인할 수 없었다.

풍화 전후 고체 시료의 비표면적 변화를 관찰하기 위하여 $\mathrm{BET}$ 분석을 수행하였다.

광물 시료의 $\mathrm{BET}$ 분석결과 Table 1 에서 볼 수 있듯이 풍 화 과정 전후 크게 차이를 발견할 수 없었다. 영동 일라이트 의 총 공극 부피 값이 $0.019 \mathrm{~cm}^{3} / \mathrm{g}$ 에 반해 풍화일라이트는 $0.018 \mathrm{~cm}^{3} / \mathrm{g}$ 로 큰 차이가 없었다. 마찬가지로, 평균 공극 직 경은 영동 일라이트가 $14.51 \mathrm{~nm}$ 에서 풍화 후 $13.68 \mathrm{~nm}$ 로 약간의 감소를 보였으나 큰 차이가 없음을 확인할 수 있다.

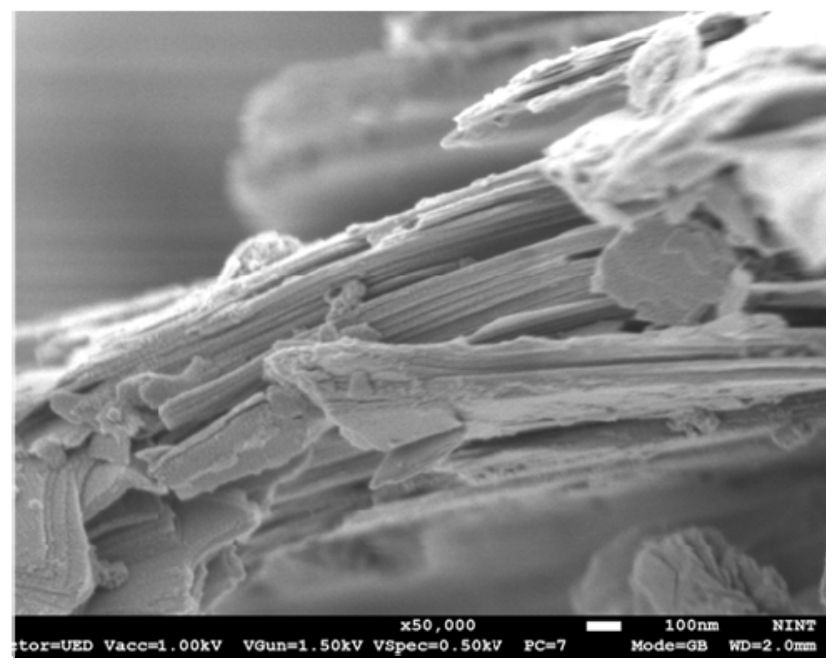

Fig. 1. Scanning electron microscopy images of YD illite and weathering illite for surface morphology analysis - (a) YD illite, $x$ 50,000; (b) Weathering illite, $x 50,000$. 
Table 1. Specific surface area, total pore volume, and mean pore diameter of illite and weathering illite.

\begin{tabular}{ccc} 
& YD illite & Weathering illite \\
Specific surface area $\left(\mathrm{m}^{2} / \mathrm{g}\right)$ & 5.2394 & 5.2489 \\
Total pore volume $\left(\mathrm{cm}^{3} / \mathrm{g}\right)$ & 0.019006 & 0.017957 \\
Mean pore diameter $(\mathrm{nm})$ & 14.51 & 13.684 \\
\hline
\end{tabular}

Table 2. (Hydrated) lonic radius and hydration energy of cations. ${ }^{28)}$

\begin{tabular}{cccc} 
& $\mathrm{K}^{+}$ & $\mathrm{Ca}^{2+}$ & 0.174 \\
Ionic radius $(\mathrm{nm})$ & 0.152 & 0.100 & 0.329 \\
Hydrated ionic radius $(\mathrm{nm})$ & 0.331 & 0.412 & 1577 \\
$-\triangle \mathrm{H}^{\circ}$ hyd $(\mathrm{kJ} / \mathrm{mole})$ & 322 & 264 \\
\hline
\end{tabular}

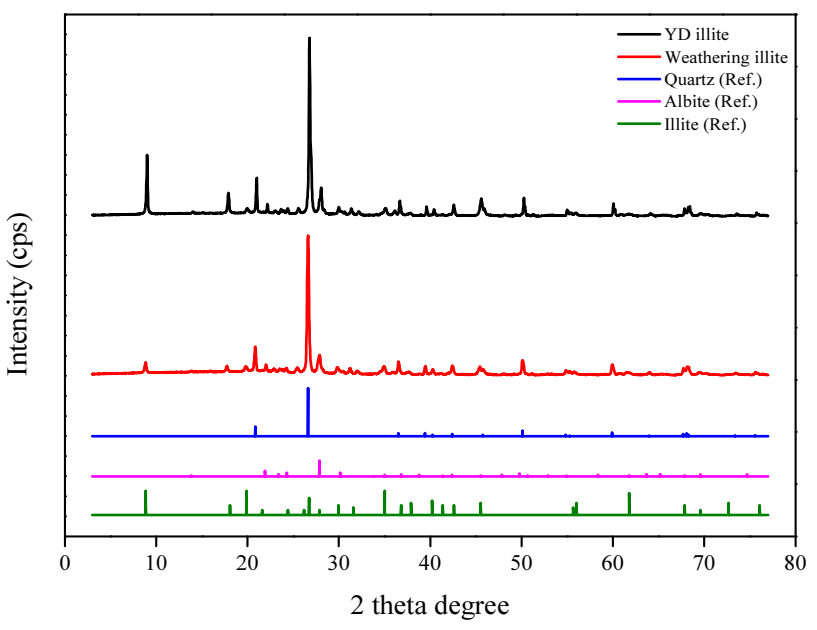

Fig. 2. XRD patterns of two solid samples.

공극의 변화는 주로 기계적(물리적) 풍화로 인해 발생하는 현상이며, ${ }^{25)}$ 본 연구에서 진행한 화학적 풍화에서는 풍화 전후 일라이트의 공극은 큰 차이가 발생하지 않았다는 것을 확인할 수 있다.

따라서, 영동 일라이트와 풍화일라이트의 구성 광물을 확 인하기 위해 XRD 분석을 실시하였다.

Fig. 2는 XRD 분석결과를 나타내며, 영동 일라이트와 풍 화일라이트 모두 석영, 장석, 그리고 일라이트가 주요 광물 로 동정되었다. 영동 일라이트와 풍화일라이트 모두 피크의 첨도와 강도가 높은 것을 보아 결정성이 뛰어나며 일라이트 의 메인 피크 $(2 \theta=9.04,17.90)$ 와 같은 형상을 보인다. 일반 적으로 영동 일라이트에 약간의 풍화가 진행될 경우, 층간 에 존재하는 칼륨 이온이 강하게 결합되어 팽창되지 못하는 상황이 발생한다. 이때, 가장자리에 존재하는 칼륨 이온만 용출이 되어 닳은 모서리를 형성하게 된다. 하지만, 영동 일 라이트가 강한 풍화 과정을 겪는 경우, 칼륨 이온이 용출되 고 빠져나온 자리에 칼슘 이온이 자리하게 되면서 층간이 팽창된다. ${ }^{26,27)}$ 양이온은 수화 상태에서 이동성을 갖는데, 용 액 내 수화된 세슘의 수화반경은 칼륨의 수화반경과 비슷하

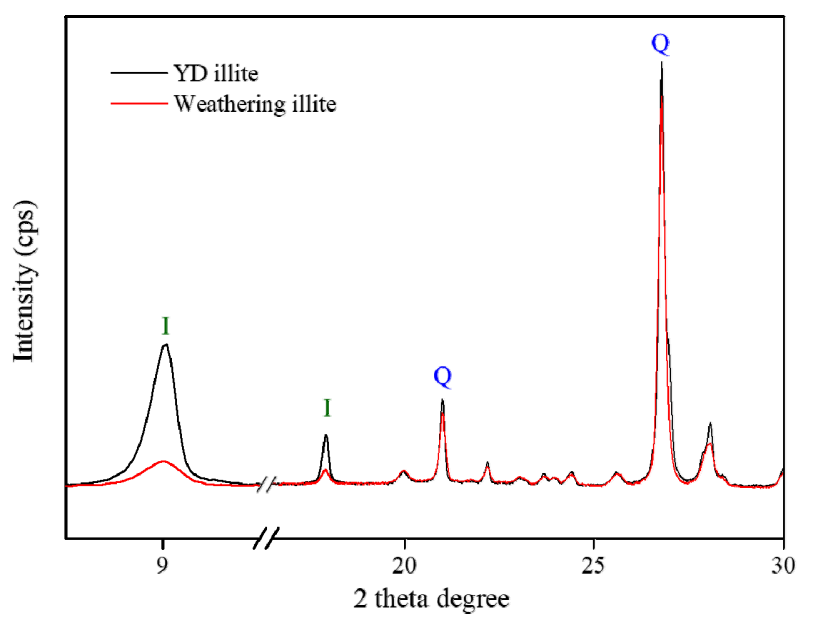

Fig. 3. Changes of peak intensity after artificial weathering ( $=$ Illite main peak, $\mathrm{Q}=$ Quartz main peak).

여 다른 양이온에 비해 쉽게 풍화된 모서리면에 진입할 수 있다. 세슘이 풍화된 모서리면에 진입하게 되면 기존의 비 수화 상태로 존재하는 칼륨과 치환을 한다. 칼륨의 수화에 너지는 세슘의 수화에너지에 비해 높으므로 칼륨은 세슘의 물분자를 빼앗아, 세슘은 비교적 안정한 비수화 상태로 풍화 된 모서리면에 흡착하게 된다. 따라서 세슘은 일라이트의 풍 화된 모서리면에 비가역적으로 흡착하게 된다(Table 2). ${ }^{7,28)}$

풍화일라이트의 풍화 정도를 보기 위하여 일라이트의 메 인 피크 $(2 \theta=9.04,17.90)$ 부근에서 피크의 형상을 확대하여

Fig. 3 에 도시하였다.

일라이트 메인 피크들은 풍화 전후 강도가 크게 변하였다. 영동 일라이트를 산처리 시 가장자리에서 컬링이 발생하여 풍화된 모서리면이 생성되는데, 이는 약간의 비정질 구조가 생성됨을 의미한다. 따라서 산처리 시 풍화가 일어나 XRD 에서 일라이트 피크의 강도가 감소하게 된다(Table 2). ${ }^{29,30)}$ 이러한 $\mathrm{XRD}$ 결과를 뒷받침하기 위하여 $\mathrm{TEM}$ 분석을 실 시하였다.

Fig. 4는 (a) 영동 일라이트, (b) 풍화일라이트의 투과 전 자 현미경 분석 결과를 보여준다. 분석 결과, 주사 전자 현 


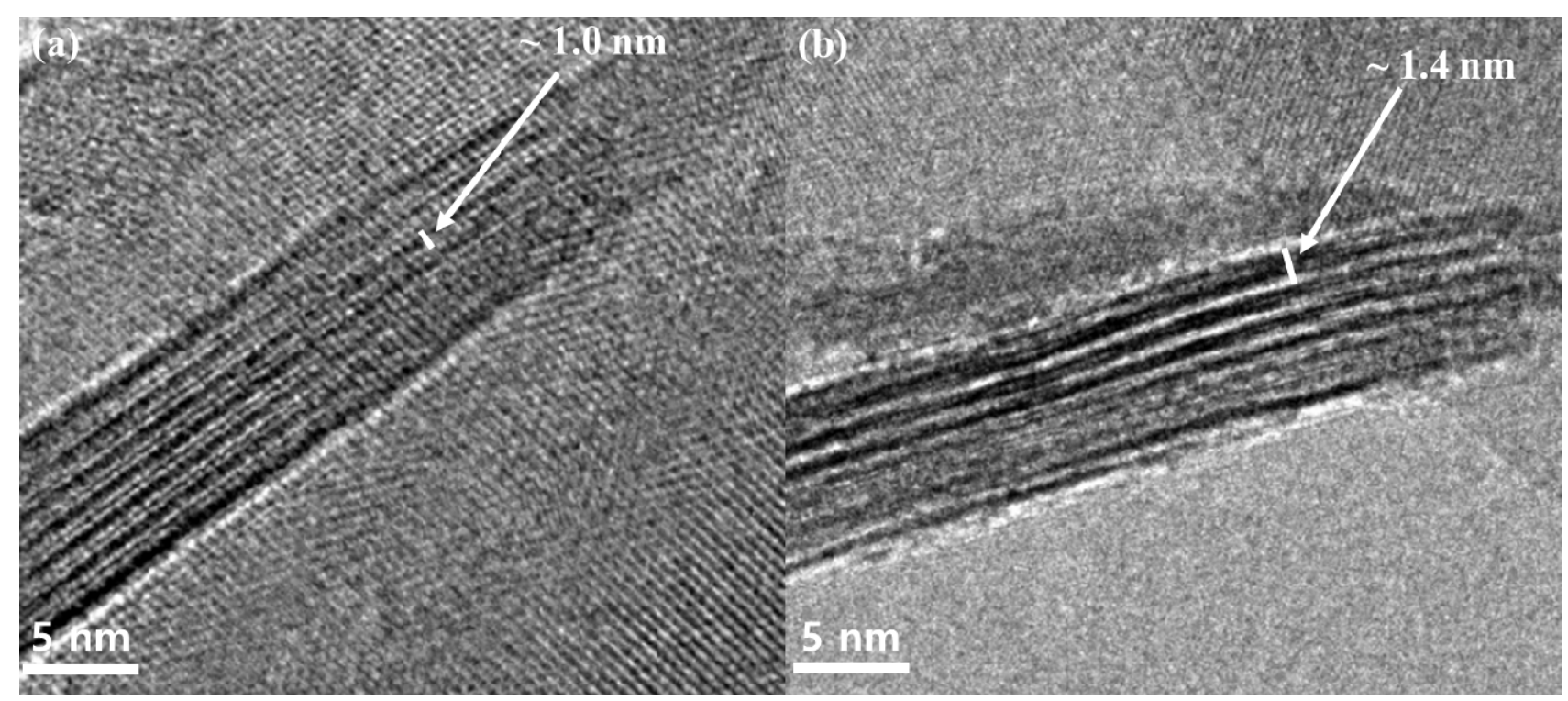

Fig. 4. TEM images of illite. (a) YD illite and (b) Weathering illite.

미경에서 분석하지 못한 수 나노미터 범위의 일라이트 구조 를 확인할 수 있었다. 풍화 전 영동 일라이트의 층간 간격은 약 $1.0 \mathrm{~nm}$ 였으며 가장자리 또한 $1.0 \mathrm{~nm}$ 의 간격을 유지하였 다. 풍화일라이트에서는 중간 부분과는 다른 형태로 가장자 리 부분에서 휘어지는 현상이 나타났으며 가장자리의 층간 거리를 측정한 결과 약 $1.4 \mathrm{~nm}$ 로 증가한 것을 알 수 있다. 이는 고온산처리의 풍화 과정을 거치면서 일라이트의 가장 자리에서 칼륨이온이 용출되고 칼슘이온이 들어가면서 층간 간격을 팽창시켜 풍화된 모서리면이 생성됨을 알 수 있다.

\section{2. 세슘 흡착}

영동 일라이트와 풍화일라이트의 산성 및 중성조건에서 의 세슘 흡착 실험 결과, 시료의 인위적 풍화 여부에 따라 흡착율에 차이를 보였다. 산성 및 중성 조건에서의 세슘 흡 착율을 Fig. 5 에 도시하였다.

산성 조건에서의 영동 일라이트와 풍화일라이트의 세슘 흡착율은 각각 약 $55 \%$ 와 $66 \%$ 로 전처리를 통해 제조된 풍 화일라이트가 약 $11 \%$ 높은 흡착율을 보였다. 또한 중성 조 건에서는 두 일라이트의 흡착율은 각각 $69 \%$ 와 95\%로 산성 조건에 비하여 큰 흡착율 차이를 보이는 것으로 나타났다.

일라이트와 같은 점토광물의 흡착은 표면흡착과 층간 양 이온과의 이온교환에 의한 흡착으로 나뉜다. ${ }^{31)}$ 일라이트 표 면에는 세슘에 선택적 흡착을 하는 풍화된 모서리면(FES) 과 세슘과 선택적 흡착을 하지 않는 표면 자리(planar site, PS), Type II (intermediate sites) 자리가 존재한다. ${ }^{32-34)}$ 풍화 된 모서리면은 세슘에 높은 친밀도와 낮은 수용성을 갖는 반면 Type II는 낮은 친밀도와 높은 수용성을 갖는다. ${ }^{32)}$

Table 3은 일라이트의 흡착 지점과 차지하는 비율을 나타 낸 표이며, 흡착 지점의 양은 표면 자리가 가장 많이 차지하

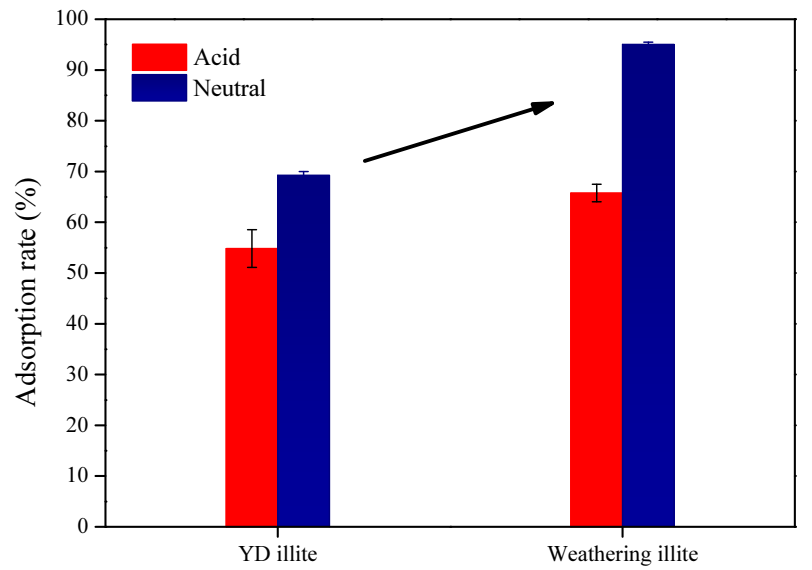

Fig. 5. Changes of adsorption rate before and after artificial weathering under acid and neutral conditions.

며 풍화된 모서리면이 가장 적게 차지하는 것을 확인할 수 있다. ${ }^{32)}$ 본 실험에서의 저농도 세슘의 흡착 특성은 풍화된 모서리면에 기인한 것으로, 풍화된 모서리면의 양이 흡착지 점에서 차지하는 비율이 낮기 때문에 세슘의 농도가 높아질 수록 일라이트의 흡착율이 떨어지는 것도 이 때문이다. ${ }^{35,36)}$ 영동 일라이트와 비교하여 풍화일라이트는 고온산처리되는 과정에서 일라이트 층간 양이온의 용출로 인하여 층간 간격 이 팽창되어 풍화된 모서리면의 양이 증가하였고, 풍화된 모 서리면은 세슘을 선택적으로 잘 흡착하기에, 이러한 구조적

Table 3. Site types and distributions for illite. ${ }^{30)}$

\begin{tabular}{cc} 
Site types & Site capacities \\
Frayed edge sites & $0.25 \%$ of the CEC $^{a}$ \\
Type II sites & $20 \%$ of the CEC \\
Planar sites & $\sim 80 \%$ of the CEC \\
\hline
\end{tabular}

${ }^{\mathrm{a}} \mathrm{CEC}=$ cation exchange in equiv. $\mathrm{kg}^{-1}$ 


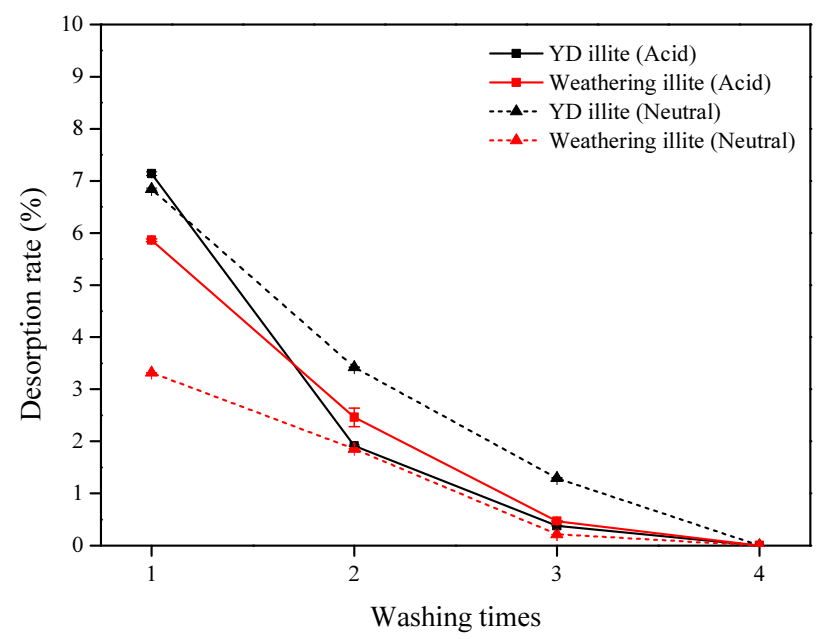

Fig. 6. Desorption rate as a function of the number of washing times under acid and neutral conditions.

변화가 세슘 흡착율 증가의 주요 요인인 것으로 판단된다. $\mathrm{pH}$ 에 따른 일라이트의 세슘 흡착율의 경우, 중성일 때가 산성일 때보다 높은 흡착율을 보인다. 이는 일라이트는 특 정 흡착지점마다 다른 세슘 흡착율을 보이며 특히 저농도 세슘의 주요 흡착지점인 풍화된 모서리면에서는 산성보다 중성에서 높은 흡착율을 보이기 때문이다. ${ }^{1,37,38)}$ 또한 일라 이트의 PZC (Point of Zero Charge)는 3.9로, ${ }^{39)}$ 높은 pH에서 는 흡착제의 표면이 음전하를 띠고 있으며 세슘은 주로 양 이온 형태로 존재하기 때문에 $\mathrm{pH}$ 가 높아질수록 흡착제와의 반응성이 커진다. 또한 낮은 $\mathrm{pH}$ 에서는 흡착제의 표면이 양 전하를 띠고 있어, 세슘과의 반응성이 감소하게 된다. 따라 서 고농도의 옥살산의 경우 강산으로 존재하기 때문에 일라 이트의 세슘 흡착율은 감소하게 되며, 산성 조건보다 중성 조건에서 영동 일라이트 및 풍화일라이트의 세슘 흡착율은 증가하게 된다. ${ }^{40-42)}$

\section{3. 세슘 탈착}

초순수 증류수를 이용한 세척 횟수에 따른 물리적 탈착율 은 Fig. 6에 도시하였다.

산성 및 중성 조건 모두 4번 세척 후 세슘의 농도가 측정 되지 않았고, 이는 흡착제 표면에 묻어있는 세슘이 모두 물 리적으로 탈착되었다고 판단된다. 침전된 시료는 건조 후 경쟁 이온인 칼륨을 이용한 화학적 탈착 실험을 진행하였 다. 산성 조건에서의 영동 일라이트와 풍화일라이트의 화학 적 탈착 실험 결과는 Fig.7에 도시하였다.

시간이 지남에 따라 일라이트에서의 세슘의 탈착율이 증 가하며, 7 일 이후에는 영동 일라이트는 약 $37 \%$ 의 탈착율을, 풍화일라이트는 $31 \%$ 의 탈착율을 나타내며 평형에 도달하 였다. 평형에 도달한 7일에서의 탈착율의 경우 풍화일라이 트의 탈착율이 영동 일라이트의 탈착율보다 낮은 결과를 나 타냈다. 풍화된 모서리면에 흡착된 세슘은 경쟁 이온인 칼

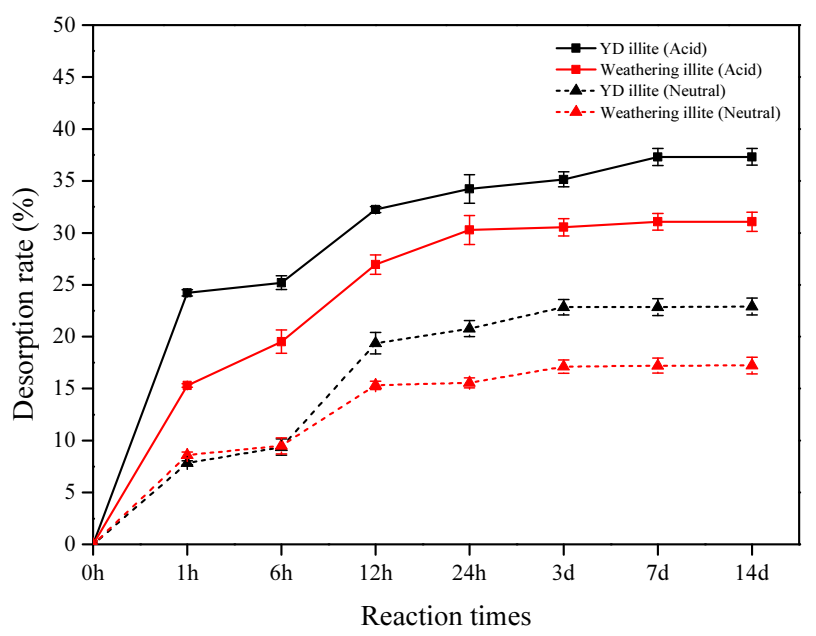

Fig. 7. Desorption rate as a function of reaction times under acid and neutral conditions.

륨의 수화에너지보다 작기 때문에 수화상태로 존재하는 칼 륨으로부터 물분자를 빼앗을 수 없어 안정된 비수화상태로 존재하게 된다. 따라서 세슘은 일라이트의 풍화된 모서리면 에 비가역적으로 흡착되며 이로 인해 풍화일라이트에서 세 슘이 덜 탈착되었다고 판단된다. ${ }^{7,28)}$

중성 조건 또한 산성 조건에서와 같이 시간이 지남에 따 라 세슘의 탈착율이 증가하였고, 중성 조건에서는 3 일 이후 영동 일라이트는 약 $23 \%$ 의 탈착율을, 풍화일라이트는 $17 \%$ 의 탈착율을 나타내며 평형에 도달하였다. 중성조건에서 풍 화일라이트의 낮은 세슘 탈착율은 산성 조건에서와 같이 풍 화된 모서리면의 선택적 세슘 흡착의 영향에 기인한 것으로 판단된다. ${ }^{7,28}$ 또한 중성 조건에서의 탈착율이 산성 조건보 다 낮았으며 이는 일라이트는 높은 $\mathrm{pH}$ 에서 표면 전하가 음 전하를 띠게 되므로 양이온으로 존재하는 세슘과 반응성이 커져 탈착율이 감소하기 때문이다. ${ }^{41)}$

따라서 저농도의 세슘이 흡착된 일라이트는 칼륨 용액과 반응하였을 때 위 Fig.7과 같이 탈착되며, 영동 일라이트를 고온산처리를 통해 인위적으로 풍화시키면 풍화된 모서리 면의 증가로 인해 산성 및 중성 조건에서 영동 일라이트보 다 탈착율이 낮아진다는 것을 확인할 수 있다.

\section{4. 결 론}

본 연구에서는 원자력발전소 운영 및 해체 시 발생하는 세슘으로 인해 오염된 원전 주변 토양을 산성 및 중성 세척 후 발생하는 2 차 폐수에서의 세슘을 제거하기 위하여 영동 지역에서 채취한 영동 일라이트를 흡착제로 사용하였다. 일 라이트는 풍화된 모서리면이라는 특이한 흡착 지점이 존재 하여 저농도의 세슘을 선택적으로 잘 흡착한다. 이러한 흡 착 지점을 증가시켜 영동 일라이트의 세슘 흡착율을 높이기 위하여 영동 일라이트를 고온산처리를 통하여 인위적으로 
풍화시켰다. XRD 분석 결과, 고온산처리 후 일라이트의 피 크의 강도가 크게 감소하였으며 이는 일라이트에 풍화가 발 생하였음을 의미한다. 투과 전자 현미경 분석 결과, 풍화 전 후 일라이트의 가장자리의 층간 간격이 $1.0 \mathrm{~nm}$ 에서 $1.4 \mathrm{~nm}$ 로 증가하였고 이를 통해 풍화된 모서리면의 생성을 입증할 수 있다. 이후 영동 일라이트와 풍화일라이트의 흡착 및 탈 착 실험을 통하여 산성 및 중성조건에서의 흡착제의 특성을 비교 및 분석하였다. 풍화일라이트는 영동 일라이트보다 흡 착율의 경우 산성 조건에서는 약 $11 \%$, 중성 조건에서는 약 $26 \%$ 증가하였고, 탈착율의 경우 산성 및 중성 조건에서 모 두 약 $6 \%$ 감소하였다. 이는 고온산처리를 통해 영동 일라이 트를 인위적으로 풍화시키면 흡착제로써의 일라이트의 성 능을 개선시킬 수 있으며 이는 토양 세척 후 발생하는 2차 폐수에서의 방사성세슘 제거를 위한 효과적인 흡착제로 활 용될 수 있음을 시사한다.

\section{Acknowledgement}

본 연구는 산업통상자원부의 재원으로 한국에너지기술평 가원(KETEP)의 에너지기술개발사업의 지원을 받아 수행한 연구입니다(No. 20181510300800).

\section{References}

1. B. Siroux, A. Wissocq, C. Beaucaire, C. Latrille, C. Petcut, J. Calvaire, M. Tabarant, M. F. Benedetti, P. E. Reiller, Adsorption of strontium and caesium onto an Na-illite and Na-illite/Na-smectite mixtures: implementation and application of a multi-site ion-exchange model, Appl. Geochem., 99, 65-74(2018).

2. S. I. Hwang, Towards efficient management of radioactivecontaminated soil and groundwater by nuclear accidents, Korea Environment Institute(2011).

3. S. M. Park, J. S. Lee, Y. H. Kim, J. S. Lee, K. T. Baek, Influence of physicochemical properties on cesium adsorption onto soil, J. Soil Groundw. Environ., 22(1), 27-32(2017).

4. S. I. Kim, J. S. Song, A study on the evaluation of cesium removal performance in soil washing process using flocculating agent, J. Radioanal. Nucl. Chem., 316(3), 1227-1232(2018).

5. M. Jang, J. S. Hwang, S. I. Choi, Sequential soil washing techniques using hydrochloric acid and sodium hydroxide for remediating arsenic-contaminated soils in abandoned iron-ore mines, Chemosphere, 66(1), 8-17(2007).

6. M. Wei, J. Chen, X. Wang, Removal of arsenic and cadmium with sequential soil washing techniques using $\mathrm{Na}_{2}$ EDTA, oxalic and phosphoric acid: optimization conditions, removal effectiveness and ecological risks, Chemosphere, 156, 252-261(2016).

7. J. Lee, S. M. Park, E. K. Jeon, K. Baek, Selective and irreversible adsorption mechanism of cesium on illite, Appl.
Geochem., 85(Part B), 188-193(2017).

8. A. F. Tag El-Din, E. A. Elshehy, M. O. Abd El-Magied, A. A. Atia, M. E. El-Khouly, Decontamination of radioactive cesium ions using ordered mesoporous monetite, RSC Adv., 8(34), 19041-19050(2018).

9. C. B. Durrant, J. D. Begg, A. B. Kersting, M. Zavarin, Cesium sorption reversibility and kinetics on illite, montmorillonite, and kaolinite, Sci. Total Environ., 610-611, 511-520(2018).

10. H. G. Cho, O. H. Park, D. H. Moon, J. Y. Do, S. O. Kim, Phosphate adsorption of Youngdong illite, Korea, J. Miner. Soc. Korea, 20(4), 327-337(2007).

11. J. P. Bellenger, S. Staunton, Adsorption and desorption of $85 \mathrm{Sr}$ and $137 \mathrm{Cs}$ on reference minerals, with and without inorganic and organic surface coatings, J. Environ. Radioact., 99(5), 831-840(2008).

12. A. J. Fuller, S. Shaw, M. B. Ward, S. J. Haigh, J. F. W. Mosselmans, C. L. Peacock, S. Stackhouse, A. J. Dent, D. Trivedi, I. T. Burke, Caesium incorporation and retention in illite interlayers, Appl. Clay Sci., 108, 128-134(2015).

13. M. L. Jackson, S. A. Tyler, A. L. Willis, G. A. Bourbeau, R. P. Pennington, Weathering sequence of clay-size minerals in soils and sediments. I: fundamental generalizations, J. Phys. Chem., 52(7), 1237-1260(1948).

14. A. Nakao, Y. Thiry, S. Funakawa, T. Kosaki, Characterization of the frayed edge site of micaceous minerals in soil clays influenced by different pedogenetic conditions in Japan and northern Thailand, Soil Science and Plant Nutrition, 54(4), 479-489(2008).

15. R. N. J. Comans, M. Haller, P. De Preter, Sorption of cesium on illite: non-equilibrium behaviour and reversibility, Geochim. Cosmochim. Acta, 55(2), 433-440(1991).

16. H. Long, P. Wu, L. Yang, Z. Huang, N. Zhu, Z. Hu, Efficient removal of cesium from aqueous solution with vermiculite of enhanced adsorption property through surface modification by ethylamine, J. Colloid Interface Sci., 428, 295-301(2014).

17. I. Bibi, B. Singh, E. Silvester, Dissolution of illite in saline-acidic solutions at $25^{\circ} \mathrm{C}$, Geochim. Cosmochim. Acta, 75(11), 3237-3249(2011).

18. G. N. Kim, W. K. Choi, C. H. Jung, J. K. Moon, Development of a washing system for soil contaminated with radionuclides around TRIGA reactors, J. Ind. Eng. Chem., 13(3), 406-413(2007).

19. J. Kim, R. Ryoo, J. Lee, D. Song, Y. J. Lee, H. B. Jun, Study on major mineral distribution characteristics in groundwater in South Korea, J. Korean Soc. Environ. Eng., 38(10), 566-573(2016).

20. J. Hwang, S. Choung, W. Shin, W. S. Han, Study on the illite modification for removal of Radioactive cesium in water environment near nuclear facilities, Econ. Environ. Geol., 51(2), 113-120(2018).

21. Q. Fan, N. Yamaguchi, M. Tanaka, H. Tsukada, Y. Takahashi, Relationship between the adsorption species of cesium and radiocesium interception potential in soils and 
minerals: an EXAFS study, J. Environ. Radioact., 138, 92-100(2014).

22. S. Kim, S. W. Kang, B. S. Kim, D. M. Oh, Y. S. Kim, Y. S. Chung, Y. H. Hwang, H. B. Wei, Synthesis of adsorbent fixed with prussian blue based by illite and adsorption of soluble radioactive cesium $\left({ }^{137} \mathrm{Cs}\right)$, J. Korean Soc. Environ. Eng., 41(1), 24-30(2019).

23. J. S. Wahlberg, M. J. Fishman, Adsorption of Cesium on Clay Minerals, Geological Survey Bulletin 1140-A, Washington, USA(1962).

24. A. Benedicto, T. Missana, A. M. Fernández, Interlayer collapse affects on cesium adsorption onto illite, Environ. Sci. Technol., 48(9), 4909-4915(2014).

25. J. H. Park, H. D. Park, Variation of physical and microstructural properties of limestone caused by artificial freezing and thawing, Tunn. Undergr. Space, 25(5), 435-449 (2015).

26. C. I. Rich, Effect of cation size and $\mathrm{pH}$ on potassium exchange in nason soil, Soil Sci., 98(2), 100-106(1964).

27. M. L. Jackson, Interlayering of expansible layer silicates in soils by chemical weathering, Eleventh National Conference on Clay and Clay Minerals, 221(1), 213-221(1977).

28. Korea Atomic Energy Research Institute, Development of decommissioning, decontamination and remediation technology for nuclear facilities, KAERI, RR-4230(2016).

29. M. Kong, L. Huang, L. Li, Z. Zhang, S. Zheng, M. K. Wang, Effects of oxalic and citric acids on three clay minerals after incubation, Appl. Clay Sci., 99, 207-214(2014).

30. S. M. Kim, I. H. Yoon, I. G. Kim, C. W. Park, Y. H. Sihn, J. H. Kim, S. J. Park, Cs desorption behavior during hydrothermal treatment of illite with oxalic acid, Environ. Sci. Pollut. Res., 27, 35580-35590(2020).

31. R. M. Cornell, Adsorption of cesium on minerals: a review, J. Radioanal. Nucl. Chem., 171(2), 483-500(1993).

32. B. Baeyens, M. H. Bradbury, Cation exchange capacity measurements on illite using the sodium and cesium isotope dilution technique: effects of the index cation, electrolyte concentration and competition: modeling, Clays Clay Miner., 52(4), 421-431(2004).

33. S. Wick, B. Baeyens, M. M. Fernandes, A. Voegelin, Thallium adsorption onto illite, Environ. Sci. Technol., 52(2), 571-580(2018).

34. A. de Koning, R. N. J. Comans, Reversibility of radiocaesium sorption on illite, Geochim. Cosmochim. Acta, 68(13), 2815-2823(2004).

35. M. H. Bradbury, B. Baeyens, A generalised sorption model for the concentration dependent uptake of caesium by argillaceous rocks, J. Contam. Hydrol., 42(2-4), 141-163(2000).
36. A. J. Fuller, S. Shaw, C. L. Peacock, D. Trivedi, J. S. Small, L. G. Abrahamsen, I. T. Burke, Ionic strength and $\mathrm{pH}$ dependent multi-site sorption of Cs onto a micaceous aquifer sediment, Appl. Geochem., 40, 32-42(2014).

37. C. Poinssot, B. Baeyens, M. H. Bradbury, Experimental studies of $\mathrm{Cs}, \mathrm{Sr}, \mathrm{Ni}$ and $\mathrm{Eu}$ sorption on Na-illite and the modelling of Cs sorption, PSI-Ber., 99-06, 1-61(1999).

38. A. Wissocq, C. Beaucaire, C. Latrille, Application of the multi-site ion exchanger model to the sorption of $\mathrm{Sr}$ and $\mathrm{Cs}$ on natural clayey sandstone, Appl. Geochem., 93, 167-177 (2018).

39. H. G. Cho, E. Y. Kim, G. Y. Jeong, Surface chemical properties of the Youngdong illite ore: the $\mathrm{pH}$ of zero proton charge and surface site density, J. Miner. Soc. Korea, 14(1), 12-20(2001).

40. C. Willms, Z. Li, L. Allen, C. V. Evans, Desorption of cesium from kaolinite and illite using alkylammonium salts, Appl. Clay Sci., 25(3-4), 125-133(2004).

41. S. A. Hussain, Ş. Demirci, G. Özbayoğlu, Zeta potential measurements on three clays from Turkey and effects of clays on coal flotation, J. Colloid Interface Sci., 184(2), 535-541(1996).

42. A. J. Fuller, S. Shaw, C. L. Peacock, D. Trivedi, I. T. Burke, EXAFS study of $\mathrm{Sr}$ sorption to illite, goethite, chlorite, and mixed sediment under hyperalkaline conditions, Langmuir, 32(12), 2937-2946(2016).

\section{Authors}

\section{Juhyeok Lee}

Division of Advanced Nuclear Engineering, Pohang University of Science and Technology, M.S. Candidate, ORCiD [D 0000-00029373-8084

\section{Jaeeun Kang}

Division of Advanced Nuclear Engineering, Pohang University of Science and Technology, M.S. Candidate, ORCiD $10000-0003-$ 0604-5632

\section{Won-Seok Kim}

Division of Advanced Nuclear Engineering, Pohang University of Science and Technology, Research Professor, ORCID (1) 0000-0003 $-3929-3720$ 